\title{
(6) OPEN ACCESS \\ Toxicant content, physical properties and biological activity of waterpipe tobacco smoke and its tobacco-free alternatives
}

\author{
Alan Shihadeh, ${ }^{1,2}$ Jens Schubert, ${ }^{3}$ Joanne Klaiany, ${ }^{4}$ Marwan El Sabban, ${ }^{5}$ \\ Andreas Luch, ${ }^{6}$ Najat A Saliba ${ }^{2,4}$
}

${ }^{1}$ Department of Mechanical Engineering, American University of Beirut, Beirut, Lebanon

${ }^{2}$ Department of Psychology, Center for the Study of Tobacco Products, Virginia Commonwealth University, Richmond, Virginia, USA ${ }^{3}$ Department of Safety of Pesticides, German Federal Institute for Risk Assessment, Berlin, Germany

${ }^{4}$ Department of Chemistry, American University of Beirut, Beirut, Lebanon

${ }^{5}$ Department of Human Morphology, American University of Beirut, Beirut, Lebanon

${ }^{6}$ Department of Chemicals and Product Safety, German Federal Institute for Risk Assessment, Berlin, Germany

\section{Correspondence to} Professor Alan Shihadeh, Department of Mechanical Engineering, PO Box 11-0236, Riad El Solh, Beirut 1107 2020, Lebanon;

as20@aub.edu.lb

Received 2 October 2014 Accepted 14 January 2015

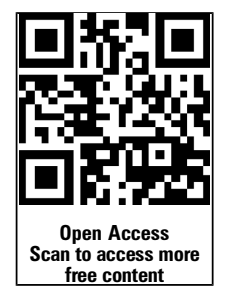

To cite: Shihadeh $A$, Schubert J, Klaiany J, et al. Tob Control 2015;24: i22-i30.

\section{ABSTRACT}

Objectives Waterpipe smoking using sweetened, flavoured tobacco products has become a widespread global phenomenon. In this paper, we review chemical, physical and biological properties of waterpipe smoke.

Data sources Peer-reviewed publications indexed in major databases between 1991 and 2014. Search keywords included a combination of: waterpipe, narghile, hookah, shisha along with names of chemical compounds and classes of compounds, in addition to terms commonly used in cellular biology and aerosol sizing.

Study selection The search was limited to articles published in English which reported novel data on waterpipe tobacco smoke (WTS) toxicant content, biological activity or particle size and which met various criteria for analytical rigour including: method specificity and selectivity, precision, accuracy and recovery, linearity, range, and stability.

Data extraction Multiple researchers reviewed the reports and collectively agreed on which data were pertinent for inclusion.

Data synthesis Waterpipe smoke contains significant concentrations of toxicants thought to cause dependence, heart disease, lung disease and cancer in cigarette smokers, and includes 27 known or suspected carcinogens. Waterpipe smoke is a respirable aerosol that induces cellular responses associated with pulmonary and arterial diseases. Except nicotine, smoke generated using tobacco-free preparations marketed for 'health conscious' users contains the same or greater doses of toxicants, with the same cellular effects as conventional products. Toxicant yield data from the analytical laboratory are consistent with studies of exposure biomarkers in waterpipe users.

Conclusions A sufficient evidence base exists to support public health interventions that highlight the fact that WTS presents a serious inhalation hazard.

\section{INTRODUCTION}

Prompted by its rapid, global rise in popularity in the past decade, ${ }^{1}$ waterpipe tobacco smoke (WTS) has been the subject of several analytical investigations. These studies typically involved connecting a waterpipe prepared according to a specific protocol to a smoking machine programmed to produce a given puffing pattern, and then capturing the resulting smoke for chemical characterisation and biological assays. While the waterpipe preparation and puff protocols used in these studies could be debated for their applicability to various populations, these machine-based studies provided rapid, unambiguous evidence that contrary to popular belief WTS contains significant concentrations of the same toxicants found in cigarette smoke, ${ }^{2-22}$ and that WTS can trigger disease pathways at the cellular level..$^{23-25}$ This evidence, later corroborated by exposure biomarker studies in humans, ${ }^{26-31}$ was deemed sufficient by public health agencies such as the WHO to call for control efforts targeting this rapidly rising tobacco use method. ${ }^{32}$ In this article, we review this evidence, focusing in particular on toxicant content, physical properties, and biological activity of WTS and waterpipe smoke generated using tobacco-free alternatives marketed to 'health conscious' users. We also present some of the methodologies adopted by WTS investigators.

\section{BACKGROUND}

\section{The narghile waterpipe}

This review focuses on the narghile waterpipe which has been at the centre of the global waterpipe use epidemic witnessed in the past decade. ${ }^{33}$ This type of waterpipe (figure 1), also commonly referred to as 'shisha' and 'hookah', is most commonly smoked using maassel, a preparation of shredded tobacco, glycerol and other additives, and sold in a broad range of flavours that mimic various fruits, candy and beverages. Because maassel is incapable of burning on its own, it is normally smoked using charcoal as a heat source. The charcoal is placed on top of the maassel, with a thin, perforated sheet of aluminium foil separating them. It is noteworthy that while maassel is the principle intended material of consumption, considerably more charcoal is consumed than maassel during a typical use session. ${ }^{10}$

During a puff, air drawn into the waterpipe passes over the charcoal and picks up coal combustion products and thermal energy. The heated air and combustion products then pass through the waterpipe head and entrain vapours emanating from the maassel. These vapours cool and recondense some distance downstream of the head to form an optically dense, white aerosol. Waterpipe smoke, therefore, consists of gases and particles emanating from the charcoal and the heated tobacco preparation. As with cigarette smoke, this aerosol includes constituents which are simply transferred from the raw material (eg, glycerol, nicotine, tobacco-specific nitrosamines (TSNAs) evaporating from the tobacco leaf), constituents which are chemically synthesised during smoking (eg, carbon monoxide, $\mathrm{CO}$ ) and constituents which are both transferred and synthesised in situ (eg, polyaromatic hydrocarbons ${ }^{34}$ ). 


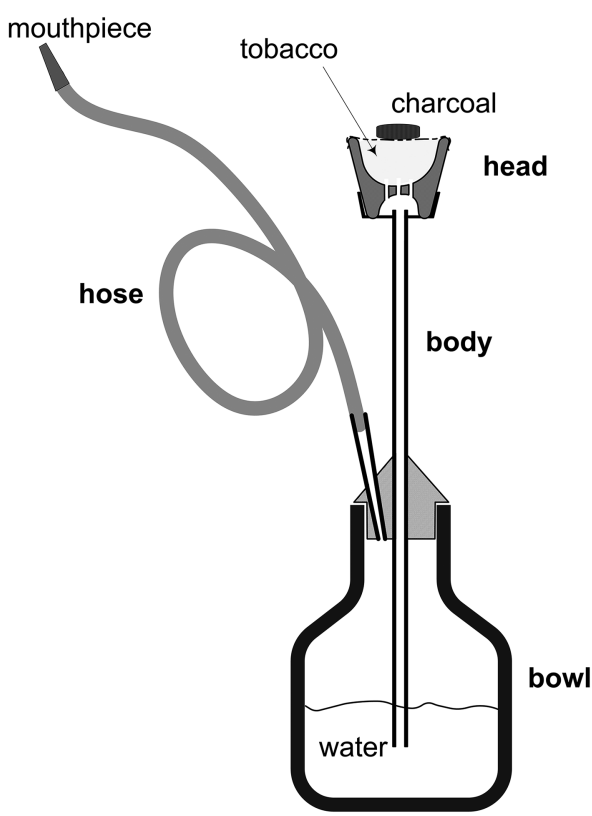

Figure 1 The head, body, bowl and hose are the primary components that make up a narghile waterpipe. To draw smoke through the water bubbler, the user must generate a vacuum sufficient to overcome the several centimetre water column residing above the submerged body outlet. The static head of the water is the primary flow resistance in the system felt by the smoker; adding or reducing the water level in the bowl modulates the drag experienced by the user. Some fraction of the drawn smoke volume (roughly one-third) remains in the head space of the water bubbler between puffs, and is displaced by fresh smoke in subsequent puffs. Flow passages are located at the base of the clay head to allow the smoke to pass into the central conduit of the body that leads to the water bowl. Because of the long path traversed by the smoke as it passes from the head, through the body, to the water bowl, and through the hose to the smoker, there are ample opportunities for gas and particulate phase deposition, diffusion, and evaporation/condensation processes to occur, as well as particle-particle coagulation. Adapted from ref. 9.

A narghile waterpipe is assembled by pressing the head onto the metal body (figure 1), using tissue paper or a rubber gasket at the joint to make a seal. The interface between the body and the glass water bowl is similarly sealed, as is the interface between the body and hose. The flexible hose is most commonly made of leather or other fibrous material, and is porous, and therefore allows air to infiltrate and dilute the smoke during every puff. The inherent variability in hose porosity, and waterpipe sealing are challenges for making reproducible measurements of toxicants in waterpipe smoke, and have led to the manufacture of at least one analytical grade, air-tight waterpipe for laboratory testing purposes (Borgwaldt Shisha Smoker).

\section{Smoke generation methods in the analytical laboratory}

Studies of WTS smoke constituents and its in vitro effects normally involve generating smoke from a waterpipe using a smoking machine that is programmed to produce a given puffing regimen, and then sampling the particle and gas phases of the smoke for subsequent assays. Numerous factors can influence WTS properties and chemistry, including the composition of the product smoked, the quality of the charcoal used, the design and construction of the waterpipe (eg, volume of the water bubbler head space, the fresh air infiltration rate of the hose during a puff), and puff topography (ie, the number of puffs drawn, the puff volume and duration, and the interval between successive puffs).

To meet scientific conventions of reproducibility, analytical laboratory studies of WTS composition and biological activity necessarily involve specifying these and other variables, ideally in some combination that represents a common waterpipe use scenario. Most studies to date have adopted some variants of the Beirut method, ${ }^{35}$ which specifies the amount of maassel tobacco preparation to be loaded in the waterpipe, a charcoal lighting and replacement regimen, an aluminium foil perforation pattern, and a steady periodic $1 \mathrm{~h}$ puffing regimen consisting of 171 puffs of $530 \mathrm{~mL}$ volume and $2.6 \mathrm{~s}$ duration, with a $17 \mathrm{~s}$ interpuff interval. This method was derived from aggregate measurements of puff topography from waterpipe users made during two field campaigns in Beirut area cafés where waterpipes were served. ${ }^{35}{ }^{36}$ Importantly, the method was found to produce realistic yields of 'tar', nicotine and $\mathrm{CO}$ when compared with measurements made using an experimental device that allowed real-time sampling of smoke generated by consumers in the same Beirut area cafés. ${ }^{35}$

Puff topography has been measured in other settings and populations, ${ }^{3738}$ and using different products, ${ }^{39}$ and found to differ considerably from the topography parameters used to derive the Beirut method. This factor alone highlights a key limitation inherent in any standard machine smoking protocol; rather than providing a method for estimating a given individual's toxicant intake, it provides a highly idealised but reproducible methodology for generating smoke for subsequent testing, and is particularly useful for exploratory work on identifying and quantifying new toxicants and biological effects in waterpipe smoke.

To examine toxicants and biological effects over a wider range of use behaviours and waterpipe products, some studies have used a 'playback' approach in which records of puff topography from sampled waterpipe-consuming individuals are reproduced in fine detail using a digital smoking machine. ${ }^{20}{ }^{22}$ By comparing toxicant levels in playback machine-produced smoke to blood concentrations of these toxicants in the individuals whose topography was recorded, it has been shown that playback provides quantitative predictions of toxicant exposure for a given sample population of waterpipe users. ${ }^{40} \mathrm{~A}$ key advantage of this approach is that it automatically accounts for interactions between product features (eg, nicotine content, flavour) and puff topography. For example, it has been reported that when provided a low-nicotine waterpipe tobacco, experienced waterpipe users puff at a higher frequency, ${ }^{41}$ likely resulting in different toxicant yields than would be measured with a puffing regimen that does not account for this behavioural difference. This 'compensatory' behaviour has been long recognised in cigarette smoking. ${ }^{42}$

In summary, waterpipe smoke toxicant content and effects have been studied using different smoke generation protocols which fall into two broad categories: steady periodic and playback. The former has the advantage of holding constant all variables, allowing for optimisation of chemical assays and investigation of dose-response characteristics in biological assays, while the latter has the advantage of producing smoke that closely resembles that which is produced by a given population using a given product. Results reported below draw from both approaches.

\section{METHODS}

For this review, the following electronic databases were searched in July 2014: Scopus, Web of Science and PubMed. Search 
terms included 'waterpipe' and its many variants (hubble bubble, shisha, hooka, goza, arghile and narghile) in combination with any of the following terms: polycyclic aromatic hydrocarbons, metals, elements, furans, furanic compounds, aldehydes, carbonyls, carbonylic compounds, tar, nicotine, CO, nitrogen oxide, TSNAs, primary aromatic amines (PAAs), volatile organic compounds (VOCs), phenols, phenolic compounds, humectants, propylene glycol, glycerol, flavours, proliferation, cytotoxicity, apoptosis, oxidative stress, reactive oxygen species, cell cycle, mutagenicity, angiogenesis and cytokines. The search was limited to papers published in English, published between 1 January 1991 and 30 September 2014. Articles were retained if they reported novel data on WTS toxicant content, biological activity or particle size distribution, and if the data were obtained using reference standards, positive/negative controls, and measures of recovery and reproducibility as appropriate.

\section{RESULTS AND DISCUSSION \\ Toxicant content}

Approximately, 300 chemicals have been identified in waterpipe tobacco and smoke to date. This number amounts to a small fraction of the 9600 compounds listed in Rodgman and Perfetti's ${ }^{43}$ most recent edition of "The Chemical Components of Tobacco and Tobacco Smoke". This embryonic state of knowledge likely reflects the comparatively small number of investigators studying waterpipe tobacco and WTS, its recent adoption as a subject for sustained study and the fact that existing analytical procedures developed to study cigarettes often are insufficient for analysing WTS.

Unsurprisingly, studies of WTS have so far focused on identifying and quantifying chemicals that appear in the 'Hoffmann list', ${ }^{44}$ a list of tobacco or tobacco smoke constituents thought to be major or contributing causative agents in tobacco-related diseases (table 1). Eighty-two toxicants have been quantified in WTS to date, including polyaromatic hydrocarbons (PAHs), heterocyclic compounds, PAAs, N-heterocyclic amines, TSNAs, carbonylic compounds, VOCs, and miscellaneous organic and inorganic compounds. In the following subsections, the information currently available on the yields of these WTS constituents is summarised.

\section{'Tar', nicotine and CO}

Ten studies ${ }^{7-10} 121921222535$ were found which report these classical smoke toxicants. Nine of these used a smoking machine, five of which ${ }^{7} 10^{12} 21$ used the Beirut method or close variants thereof. Monzer et $a l^{9}$ used the same puff volume, duration and interpuff interval as the Beirut method, but a smaller puff number (105) and less charcoal $(5.8 \mathrm{~g})$. Shihadeh $^{19}$ used a different standard smoking regime (100 puffs, $300 \mathrm{~mL}$ puff volume, $3 \mathrm{~s}$ puff duration, $30 \mathrm{~s}$ interpuff interval, $10 \mathrm{~g}$ waterpipe tobacco, approximately $5.8 \mathrm{~g}$ charcoal). Two studies 22 used playback methodology to reproduce human puffing patterns. Finally, Katurji et $a l^{35}$ applied an in situ measurement device to determine the levels of 'tar', nicotine, $\mathrm{CO}$ and water directly in the smoke generated during real-life smoking in cafés.

As shown in table 1, the amounts of 'tar' found in WTS range from 242 to $2350 \mathrm{mg} / \mathrm{session}$. The results depend on the applied smoking protocol. For studies that used the Beirut method, the range of 'tar' yields ranged from 802 to $2350 \mathrm{mg} /$ session. The water content in WTS was determined in three studies $^{12} 2135$ and ranged from 548 to $1760 \mathrm{mg} / \mathrm{session}$. The levels of nicotine found in WTS ranged from 1.04 to $7.75 \mathrm{mg} /$ session. ${ }^{10} 12 \quad 192122 \quad 35$ If no water is used in the bowl, the amount of nicotine in WTS increased from 2.11 to $9.29 \mathrm{mg} /$ session. ${ }^{19}$ However, the amount drops below $0.01 \mathrm{mg} / \mathrm{session}$ when an herbal tobacco is smoked. ${ }^{22}$ The amount of CO found in WTS range from 57.2 to $367 \mathrm{mg} /$ session and depends mainly on the amount of charcoal used for smoking. ${ }^{7-10} 122122 \quad 2535$ By using electric heating, the amount of $\mathrm{CO}$ can be reduced to $5.7 \mathrm{mg} /$ session. $^{9}$ Furthermore, the CO content is also influenced by the material of the hose (leather or plastic) used. ${ }^{10}$ Compared with cigarette smoke, the yields of 'tar', nicotine and $\mathrm{CO}$ are considerably higher in WTS (table 1).

\section{Nitric oxide}

Nitric oxide (NO) was measured in three studies reported in the literature. ${ }^{7} 22 \quad 25$ Two of these $22 \quad 25$ used human playback smoking and reported averages of 411 and $440 \mu \mathrm{g} / \mathrm{session}$, respectively. The third study, using the Beirut method, found an average of $325 \mu \mathrm{g} / \mathrm{session}$. These yields are similar to those found with cigarettes (table 1).

\section{Carbonylic compounds}

Four studies were found in the literature that reported yields of carbonylic compounds in WTS. ${ }^{2} 71322$ The results are summarised in table 1 . Three studies ${ }^{2} 713$ reported results from WTS generated using the Beirut method, whereas the fourth study ${ }^{22}$ utilised playback smoking. Other than the smoke generation method, there are additional differences across studies, for example, use of plastic versus leather hoses, the sampling method and the chemical analysis method.

It is noteworthy that the levels reported by Schubert et al, ${ }^{13}$ Hammal et $a l^{7}$ and Shihadeh et $a l^{22}$ are comparable to one another and to yields from a single cigarette, while those of $\mathrm{Al}$ Rashidi et $a l^{2}$ are much higher. All four studies found that acetaldehyde exhibited the highest concentration in WTS followed by formaldehyde and acetone. Schubert et al ${ }^{13}$ demonstrated that carbonylic compound yields are strongly influenced by the peak temperature reached in the tobacco, with higher temperatures resulting in greater yields.

\section{Polycyclic aromatic hydrocarbons}

Yields of the 16-Environmental Protection Agency PAHs ranging from 5000 to $13000 \mathrm{ng} / \mathrm{session}$ have been reported in three studies that used the Beirut method $^{9}$ or an abbreviated version of it. ${ }^{24}$ Using playback smoking ${ }^{22}$ resulted in similar PAH yields as those found with the Beirut method.

Interestingly, by comparing the yields of conventional WTS and that generated using an electrical heater in place of charcoal, Monzer et $a l^{9}$ determined that most of the PAH originates in the charcoal. For example, benzo[a]pyrene, a potent carcinogen, dropped from 170 to $9 \mathrm{ng} /$ session when electrical heating was substituted for charcoal. ${ }^{9}$

\section{Tobacco-specific nitrosamines}

TSNAs occur both in waterpipe tobacco and WTS. Currently, two studies on the determination of TSNAs in WTS are available (table 1). The first study, by Schubert et al, ${ }^{12}$ reports on the levels of $N$-nitrosoanatabine, 4-(methylnitrosoamino)-1(3-pyridinyl)-1-butanone (NNK), $N^{\prime}$-nitrosonornicotine and $\mathrm{N}$-nitrosoanabasine in waterpipe tobacco and WTS. The results showed that the levels of these four TSNAs were one to two orders of magnitude lower in maassel than in cigarette tobacco. This was partially explained by the fact that maassel is only approximately one-third tobacco, and thus the added humectants and flavourings dilute the concentration of TSNAs, which, as their name implies, are only found in tobacco. The second study, 
Table 1 Toxicants yields from waterpipes (per use-session) and cigarettes (per cigarette)

\begin{tabular}{|c|c|c|c|c|c|}
\hline Yield per unit smoked & IARC class* & $\begin{array}{l}\text { Hoffmann list } \\
\text { 'causative agent' }\end{array}$ & Cigarette & Waterpipe & Reference \\
\hline T/N/CO/NO (mg) & & & & & 7-10 1219212225354748 \\
\hline Tar & - & CVD, chronic obstructive lung disease, lung cancer & $1-27$ & $242-2350$ & \\
\hline Nicotine & - & Tobacco dependence & $0.1-3$ & $>0.01-9.29$ & \\
\hline $\mathrm{CO}$ & - & CVD & $14-23$ & $5.7-367$ & \\
\hline Water & - & - & & $548-1760$ & \\
\hline NO & - & CVD, chronic obstructive lung disease & $0.100-6.00$ & $0.325-0.440$ & \\
\hline Carbonylic compounds $(\mu \mathrm{g})$ & & Chronic obstructive lung disease, lung/larynx cancer & & & 27132249 \\
\hline Formaldehyde & 1 & & $20-100$ & $36-630$ & \\
\hline Acetaldehyde & $2 B$ & & $400-1400$ & $120-2520$ & \\
\hline Acetone & - & & - & $20.2-118$ & \\
\hline Acrolein & 3 & & $60-240$ & $10.1-892$ & \\
\hline Propionaldehyde & - & & $48.4 \dagger$ & $5.71-403$ & \\
\hline Methacrolein & - & & - & $12.2-106$ & \\
\hline Butyraldehyde & - & & - & $10.9-70.6$ & \\
\hline Benzaldehyde & - & & - & BLQ (0.339) & \\
\hline Tobacco-specific nitrosamines (ng) & & Lung/larynx/oral cavity/oesophageal/bladder cancer & & & 41249 \\
\hline NAT & 3 & & - & 103 & \\
\hline NNK & 1 & & $80-770$ & LOD-46.4 & \\
\hline NNN & 1 & & $120-3700$ & 34.3 & \\
\hline NAB & 3 & & - & 8.45 & \\
\hline Primary aromatic amines (ng) & & Urinary bladder cancer & & & 1450 \\
\hline$m$-PDA & 3 & & - & 6.50 & \\
\hline ANL & 3 & & $251.6 \ddagger$ & 31.3 & \\
\hline $4,4^{\prime}-\mathrm{ODA}$ & $2 \mathrm{~B}$ & & - & 28.0 & \\
\hline 0 -ASD & $2 B$ & & - & BLQ (3.76) & \\
\hline $4-C A$ & $2 B$ & & - & BLQ (3.39) & \\
\hline 2-ANP & 1 & & $1-334$ & 2.84 & \\
\hline 1-ANP & 3 & & $17.0 \ddagger$ & 6.20 & \\
\hline 3,5-DCA & - & & - & BLQ (3.77) & \\
\hline $2-A B P$ & - & & - & 3.33 & \\
\hline Furanic compounds $(\mu \mathrm{g})$ & & & & & 11 \\
\hline HMF & - & & - & $2420-62300$ & \\
\hline FFA & - & & - & $55.7-552$ & \\
\hline 2-FA & - & & - & $32.0-401$ & \\
\hline $2-\mathrm{F}$ & - & & - & $29.6-206$ & \\
\hline 2-FMK & - & & - & $4.77-12.5$ & \\
\hline $5-M-2-F$ & - & & - & $4.62-215$ & \\
\hline Polycyclic aromatic hydrocarbons (ng) & & Lung/larynx cancer, oral cavity cancer & & & 3912182249 \\
\hline Naphthalene & $2 B$ & & $360.8 \dagger$ & $30-3860$ & \\
\hline Acenaphtylene & - & & $71.6+$ & $42-700$ & \\
\hline Acenaphthene & 3 & & $56.8 \dagger$ & $25-17260$ & \\
\hline Fluorene & 3 & & $189.2 \dagger$ & $26-437$ & \\
\hline Phenanthrene & 3 & & $138.9 \dagger$ & $1277-2650$ & \\
\hline Anthracene & 3 & & $62.3 \dagger$ & $133-6280$ & \\
\hline Fluoranthene & 3 & & $52.7 \dagger$ & $354-2380$ & \\
\hline Pyrene & 3 & & $44.8 \dagger$ & $30-12950$ & \\
\hline Benzo[a]anthracene & $2 B$ & & $20-70$ & 30-15 190 & \\
\hline Chrysene & $2 B$ & & - & ND-124 & \\
\hline Benzo[k]fluoranthene & $2 B$ & & $6-12$ & ND-370 & \\
\hline Benzo $[b]$ fluoranthene & 2B & & $4-22$ & ND-170 & \\
\hline Benzo[a]pyrene & 1 & & $20-40$ & ND-307 & \\
\hline Benzo $[g, h, i]$ perylene & 3 & & - & ND-140 & \\
\hline Dibenz $[a, h]$ anthracene & $2 \mathrm{~A}$ & & 4 & ND-147 & \\
\hline Indeno[1,2,3-cd]pyrene & $2 B$ & & $4-20$ & ND-183 & \\
\hline Heavy metals (ng) & & Cardiovascular, lung/larynx cancer & & & 319 \\
\hline Lead & $2 B$ & & $34-85$ & $200-6870$ & \\
\hline Copper & - & & - & $1300-2300$ & \\
\hline Zinc & - & & - & $1100-1400$ & \\
\hline
\end{tabular}


Table 1 Continued

\begin{tabular}{|c|c|c|c|c|c|}
\hline Yield per unit smoked & IARC class* & $\begin{array}{l}\text { Hoffmann list } \\
\text { 'causative agent' }\end{array}$ & Cigarette & Waterpipe & Reference \\
\hline Chromium & 1 & & $4-70$ & $250-1340$ & \\
\hline Nickel & 1 or $2 B \S$ & & ND-600 & $300-900$ & \\
\hline Cobalt & $2 B$ & & $0.13-0.2$ & $70-300$ & \\
\hline Arsenic & 1 & & $40-120$ & 165 & \\
\hline Boron & - & & - & $350-1310$ & \\
\hline Beryllium & 1 & & 0.5 & 65 & \\
\hline Volatile organic compounds ( $\mu \mathrm{g}$ ) & & & & & 16 \\
\hline Isoprene & $2 \mathrm{~B}$ & & $200-400$ & 4.00 & \\
\hline Benzene & 1 & & $20-70$ & 271 & \\
\hline Toluene & 3 & & $5-90$ & 9.92 & \\
\hline Ethylbenzene & $2 B$ & & - & 1.00 & \\
\hline$p$-Xylene & 3 & & - & 0.929 & \\
\hline$m$-Xylene & 3 & & - & 2.47 & \\
\hline Pyridine & 3 & & $20-200$ & 4.76 & \\
\hline o-Xylene & 3 & & - & BLQ & \\
\hline Styrene & $2 \mathrm{~B}$ & & 10 & 1.27 & \\
\hline Quinoline & - & & $2-4$ & BLQ & \\
\hline Phenolic compounds ( $\mu \mathrm{g}$ ) & & Lung/larynx cancer & & & 1617 \\
\hline Hydroquinone & 3 & & $30.9 \dagger$ & 21.7-110.7 & \\
\hline Resorcinol & 3 & & $0.474 t$ & $1.689-1.87$ & \\
\hline Catechol & $2 B$ & & $90-2000$ & $166-316.1$ & \\
\hline Phenol & 3 & & 170 & $3.21-58.03$ & \\
\hline Guaiacol & - & & $1.00 t$ & 7.00 & \\
\hline$m$-Cresol & - & & $6.05^{\Uparrow}$ & $2.37^{\Uparrow}-4.655$ & \\
\hline$p$-Cresol & - & & - & - -5.375 & \\
\hline o-Cresol & - & & $2.09 \dagger$ & $2.93-4.409$ & \\
\hline \multicolumn{6}{|l|}{ Others (mg) } \\
\hline Propylene glycol & - & & - & 211 & 12 \\
\hline Glycerol & - & & - & 423 & 12 \\
\hline Vanillin & - & & - & 3.192 & 17 \\
\hline Ethyl vanillin & - & & - & 0.616 & 17 \\
\hline Benzyl alcohol & - & & - & 0.232 & 17 \\
\hline Biological components & & & & & 8 \\
\hline Ergosterol (ng) & - & & - & 84.4 & \\
\hline LPS (pmol) & - & & - & 1800 & \\
\hline
\end{tabular}

Unless otherwise noted, cigarette data are taken from Hoffmann et al. ${ }^{44}$

*IARC classification groups: $1=$ carcinogenic to humans; $2 \mathrm{~A}=$ probably carcinogenic to humans; $2 \mathrm{~B}=$ possibly carcinogenic to humans; $3=$ not classifiable as to its carcinogenicity to humans.

†3R4F reference cigarette.

$\ddagger 2 R 4 F$ reference cigarette.

$\S$ Depends on its form.

TCombined values for $m / p$-cresol.

1-ANP, 1-naphthylamine; 2-ABP, 2-aminobiphenyl; 2-ANP, 2-naphthylamine; 2-F, 2-furaldehyde; 2-FA, 2-furoic acid; 2-FMK, 2-furyl methyl ketone; 3,5-DCA, 3,5-dichloroaniline;

4,4'-ODA, 4,4'-oxydianiline; 4-CA, p-chloroaniline; 5-M-2-F, 5-methyl-2-furaldehyde; ANL, aniline; BLQ, below limit of quantification; CO, carbon monoxide; CVD, cardiovascular disease; FFA, furfuryl alcohol; HMF, 5-(hydroxymethyl)-2-furaldehyde; IARC, International Agency for Research on Cancer; LOD, limit of detection; LPS, lipopolysaccharide; $m$-PDA,

$m$-phenylenediamine; ND, not detected; NAB, N-nitrosoanabasine; NAT, N-nitrosoanatabine; NNK, 4-(methylnitrosoamino)-1-(3-pyridinyl)-1-butanone; NNN, $N^{\prime}$-nitrosonornicotine; NO, nitric oxide; $o-A S D, o$-anisidine.

by Amor et $a l,{ }^{4}$ reported finding no NNK in WTS, though the limit of detection was not specified. ${ }^{4}$

Biomonitoring studies confirm that a single waterpipe use systemically exposes individuals to TSNAs. ${ }^{26} 303145$ These four studies, published between 2011 and 2013, clearly demonstrated that urinary excretion of 4-(methylnitrosamino)-1-(3-pyridyl)1-butanol, the lead metabolite of NNK, increased following waterpipe smoking, though by a considerably smaller amount than occurs when smoking a cigarette. ${ }^{26} 303145$

\section{Heavy metals}

Using two different machine smoking protocols and tobacco flavours, concentrations of heavy metals ranged between 200 and
$7000 \mathrm{ng} / \mathrm{session}$ (table 1). ${ }^{3} 19$ Compared with cigarette smoke, most toxic metals-cobalt, chromium, nickel, cadmium and lead -were present at much higher concentrations in WTS.

\section{Primary aromatic amines}

One study reported PAAs in WTS. ${ }^{14}$ Schubert et $a l^{14}$ showed that among the 31 compounds analysed only 9 could be detected in WTS: $m$-phenylenediamine, aniline, 4,4'-oxydianiline, $o$-anisidine, $p$-chloroaniline, 2-naphthylamine, 1-naphthylamine, 3,5-dichloroaniline and 2-aminobiphenyl. Among these, aniline and $4,4^{\prime}$-oxydianiline were found with the highest concentrations (see table 1). Compared with a single cigarette, a single waterpipe yields considerably less aromatic amines. 


\section{Furanic compounds}

Because maassel contains humectants and flavourings, heating it can induce a range of chemical conversions via sugar caramelisation and the Maillard reaction. Such reactions and others can generate furanic compounds. This was recently demonstrated by Schubert et al. ${ }^{11}$ The authors analysed WTS of five commercially available waterpipe tobacco brands and detected considerable levels of these species. The results are compiled in table 1. Among the nine compounds analysed compound 5-(hydroxymethyl)-2-furaldehyde was found in the highest concentrations. In addition, furfuryl alcohol, 2-furoic acid, 2furaldehyde, 2-furyl methyl ketone and 5-methyl-2-furaldehyde were also detected. The authors also showed that the generation of these compounds depended mainly on the temperature attained in the tobacco during the smoking process, as well as on the levels of carbohydrates and humectants in the unburned tobacco. In general, a higher temperature, a lower content of humectants and a higher content of carbohydrates led to increased levels of furanic compounds.

\section{Volatile organic compounds}

According to Fowles and Dybing ${ }^{46}$ VOCs include some of the most harmful substances present in tobacco smoke, for example, 1,3-butadiene, acrylonitrile and benzene. A recent biomonitoring study by Jacob et $a l^{31}$ indicated that WTS may contain high quantities of benzene as the authors found high levels of its metabolite, that is, phenylmercapturic acid, in the urine of waterpipe smokers. Recently, Schubert et $a l^{16}$ showed that WTS contains up to $271 \mu \mathrm{g} / \mathrm{session}$ benzene, a several fold higher yield than found with cigarettes (see table 1). On the other hand 1,3-butadiene and acrylonitrile were not detected in WTS. This finding is also consistent with the results presented by Jacob et $a .^{31}$ Furthermore, Schubert et $a l^{16}$ showed that benzene is mainly released by the burning charcoal. The same applies for toluene, whereas isoprene and pyridine mainly originate from the heated tobacco. ${ }^{16}$

\section{Phenolic compounds}

Two studies on phenolic compounds were identified in the literature. Sepetdjian $e t a l^{17}$ utilised a derivatisation step with subsequent gas chromatography-mass spectrometry (GC-MS) detection to quantify seven phenolic compounds in WTS, whereas Schubert et al $^{16}$ used reverse-phase high-performance liquid chromatography with fluorescence detection to quantify eight phenolic compounds in WTS. Both studies found that catechol and hydroquinone were present in the highest concentrations. In total Sepetdjian et al ${ }^{17}$ detected $501 \mu \mathrm{g} / \mathrm{session}$ of the analysed phenolic compounds, whereas Schubert et $a l^{16}$ reported $205 \mu \mathrm{g} / \mathrm{session}$. These results summarised in table 1 indicate that a single waterpipe yields similar amounts of these compounds as a single cigarette.

\section{Other}

A two-part study by El-Aasar et al $^{5}{ }^{6}$ in 1991 applied either GC-MS or atomic absorption spectroscopy detection for the identification of numerous organic constituents and metals. In total, the authors identified 142 organic substances including alkaloids, aldehydes or ketones and 16 metals to be present in WTS. Recently Schubert et $a l^{12}$ showed that WTS also contains high levels of the humectants propylene glycol and glycerol. Since in addition to these humectants waterpipe tobacco contains several flavorings, ${ }^{15}$ it can be assumed that these will also be found in the smoke. For example, Sepetdjian et al ${ }^{17}$ found that WTS can contain large quantities of vanillin, ethyl vanillin and benzyl alcohol. Finally, Markowicz et $a l^{8}$ found ergosterol and lipopolysaccharide in WTS, indicating that WTS is also a bioaerosol that may contain fungal and bacterial components.

\section{Biological activity}

Three studies have examined biological activity of WTS using in vitro culture systems. ${ }^{23-25}$ It was found that Beirut methodgenerated WTS elicited deleterious effects on cell function in human lung epithelial cells ${ }^{24}$ and vascular endothelial cells. ${ }^{23}$ These studies implicated waterpipe smoke as a contributing factor in the pathogenesis of chronic obstructive pulmonary disease and vascular disease by impairing cellular growth (cell cycle arrest) and cell repair, and inducing inflammation, oxidative stress, impaired vasodilation, cellular senescence, increased levels of matrix metalloproteinases and attenuation of angiogenesis. Using playback WTS and smoke generated with tobaccofree products, it was also reported ${ }^{25}$ that tobacco-free waterpipe smoke induced cellular dysfunction on human lung cells on par with tobacco-containing products.

\section{Particle size distribution}

Key carcinogens in tobacco smoke such as benzo(a)pyrene and heavy metals are predominantly delivered in submicron sized particles. The location and extent to which inhaled particles deposit in the respiratory tract is central to the question of toxicant delivery and subsequent effects; for example, the effective dose of a given toxicant to the lung is the product of the toxicant mass inhaled and the fraction that deposits in the lung. Experimental studies of cigarette smokers indicate that 22-89\% of the mainstream smoke particles inhaled with each puff remain in the smoker. ${ }^{51}{ }^{52}$ It is generally accepted that the detailed physical properties of tobacco smoke particulate matter determine the deposition fraction and location, which in turn determine the occurrence, type and location of tumours found in the respiratory system. Key among these properties is particle size distribution.

Two studies ${ }^{53} 54$ of mainstream WTS particle size distributions have been reported in the literature. Using a differential mobility analyser and laser spectrometer, Monn et $a l^{53}$ scanned particle diameters ranging from 0.01 to $10 \mu \mathrm{m}$ in machinegenerated WTS (two $5 \mathrm{~s}$ puffs per minute, $1 \mathrm{~L} /$ puff) and cigarette smoke. The method involved injecting individual puffs of WTS or cigarette smoke into a $113 \mathrm{~L}$ chamber filled with fresh air, resulting in a diluted smoke sample for subsequent particle size analysis. They reported a number mean diameter of $0.04 \mu \mathrm{m}$ for WTS, compared with about $0.3 \mu \mathrm{m}$ for cigarette smoke. Becquemin et $a l^{54}$ utilised an electrical low-pressure impactor to determine WTS particle mass distributions, in a diameter range of $0.028-10 \mu \mathrm{m}$. They reported a mass median diameter for $0.24 \mu \mathrm{m}$ for WTS particles. Results from these studies suggest that WTS is a submicron aerosol with capability of depositing in the human respiratory tract in a manner similar to cigarette smoke. It should be noted however that both studies likely suffered from bias due to particle evaporation before or during sizing. Such evaporation would result in underestimation of the true particle size. In the case of Monn et al, ${ }^{53}$ evaporation would be expected in the setup employed because the setup involved trapping and diluting WTS with a large quantity of fresh air prior to sizing. In the case of Becquemin et al, ${ }^{54}$ particles likely partially evaporated during transit through the lowpressure stages of the impactor. Further studies are needed which account for the high volatility composition of WTS particles. 


\section{Is smoke generated by tobacco-free waterpipe products less toxic?}

This question has been addressed in two studies ${ }^{72}$ that directly compared toxicant content of smoke generated using tobaccocontaining and tobacco-free mixtures, and one study that directly compared in vitro biological effects of the two types of products. ${ }^{25}$ Using the Beirut method, Hammal et $a l^{7}$ compared volatile aldehydes, PAHs, NO, CO, 'tar' and nicotine yields for smoke generated using a tobacco-based waterpipe product and three tobacco-free products. Shihadeh et $a l^{22}$ measured the same toxicants using a playback approach with puff topography recordings of 31 participants who smoked a waterpipe in a double-blind controlled laboratory study, once using a tobaccobased product of the participants choice, and once using flavour-matched tobacco-free product (table 2). While both studies found that nicotine was present only in the smoke of the tobacco-based products, every other toxicant measured using the tobacco-free products equalled or exceeded those measured using the tobacco-based products. Consistent with these findings, Shihadeh et $a l^{25}$ found that waterpipe smoke produced using both types of waterpipe products markedly reduced cell proliferation, caused cell cycle arrest and increased cell doubling time in human alveolar cells. There were no significant differences across product in any measure. Taken together, these studies indicate that while using non-tobacco products presents no risk of nicotine exposure, smoking a tobacco-free waterpipe product very likely presents no less disease risk than smoking a conventional tobacco-based product.

\section{DISCUSSION}

Smoking machine studies over the past decade have begun to elucidate the toxicant content and properties of waterpipe

Table 2 Direct comparison of toxicant yields from tobacco-based and tobacco-free waterpipe products, adapted from Shihadeh et al..$^{25}$

\begin{tabular}{lccc}
\hline & \multicolumn{2}{l}{ Waterpipe preparation } & \\
\cline { 2 - 3 } (mean $\pm 95 \%$ Cl) & & \\
\cline { 2 - 3 } Toxicant & Tobacco & Non-tobacco & p Value \\
\hline 'Tar' (mg) & $464 \pm 159$ & $513 \pm 115$ & NS \\
Nicotine (mg) & $1.04 \pm 0.30$ & $<0.01$ & $<0.001$ \\
Carbon monoxide (mg) & $155 \pm 49$ & $159 \pm 42$ & NS \\
Nitric oxide (mg) & $437 \pm 207$ & $386 \pm 116$ & NS \\
Polyaromatic hydrocarbons (ng) & & & \\
$\quad$ Fluoranthene & $385 \pm 74$ & $448 \pm 132$ & NS \\
Pyrene & $356 \pm 70$ & $444 \pm 125$ & NS \\
Benzo[a]anthracene & $86.4 \pm 15.2$ & $113 \pm 46$ & NS \\
Chrysene & $106 \pm 16$ & $124 \pm 36$ & NS \\
Benzo[b+k]fluoranthenes & $64.7 \pm 11.3$ & $72.9 \pm 12.6$ & NS \\
Benzo[a]pyrene & $51.8 \pm 12.9$ & $66.1 \pm 17.8$ & NS \\
Benzo[g,h,i]perylene & $33.6 \pm 10.2$ & $39.6 \pm 10.7$ & NS \\
Indeno[1,2,3-cd]pyrene & $47.3 \pm 10.7$ & $44.3 \pm 10.4$ & NS \\
Carbonylic compounds ( $\mu \mathrm{g})$ & & & \\
$\quad$ Formaldehyde & $58.7 \pm 21.6$ & $117.6 \pm 78.7$ & NS \\
Acetaldehyde & $383 \pm 121$ & $566 \pm 370$ & NS \\
Acetone & $118 \pm 36$ & $163 \pm 68$ & NS \\
Propionaldehyde & $51.7 \pm 15.3$ & $98.4 \pm 65.0$ & NS \\
Methacrolein & $12.2 \pm 4.4$ & $20.4 \pm 9.7$ & NS \\
\hline Show val & &
\end{tabular}

Shown values are mean $\pm 95 \% \mathrm{Cl}$. Smoke was generated by playback of 62 ad-lib smoking sessions recorded from 31 waterpipe users, each of who completed two smoking bouts in a controlled clinical setting: once using a preferred tobacco-based product, and once using a flavour-matched tobacco-free product.

NS, not significant. smoke using modern analytical methods and reliable smoke generation and sampling protocols. These studies have largely focused on what are considered key causative agents in smoking-related disorders in cigarette smokers: nicotine, 'tar', $\mathrm{CO}, \mathrm{PAHs}$, nitrosamines, volatile aldehydes, NO, phenols and heavy metals, and have generally found that during a typical waterpipe use session, the user will draw significant doses of toxicants, ranging from less than one to tens of cigarette equivalents, depending on the toxicant in question, as well as the particular combination of puffing regimen, maassel type, charcoal composition, and waterpipe design and construction employed in a given study. Available data also indicate that, like cigarette smoke, many of these toxicants are delivered in submicrometer sized aerosol particles that can reach the lower airways. In addition, exposing human lung and aortic cells to WTS particles has been found to trigger inflammatory response pathways that can lead to arterial and pulmonary diseases. In short, evidence generated in the analytical laboratory to date clearly points to the notion that WTS contains significant doses of toxicants, packaged in a respirable aerosol that induces deleterious effects in cells, and therefore presents a significant inhalation hazard.

Importantly, findings from the analytical laboratory are corroborated by blood and urinary exposure biomarker data gathered in clinical studies of waterpipe users. Several studies have investigated acute, multiday and long-term exposure to $\mathrm{CO}$, nicotine, PAHs and/or TSNAs. ${ }^{26-31}$ These have shown that waterpipe smoking results in significant uptake of all of these compounds, and that, compared with levels measured in cigarette smokers, waterpipe smokers attain much greater $\mathrm{CO}$ exposure, significantly greater exposure to PAHs, similar exposure to nicotine, and significantly lower exposure to TSNAs. ${ }^{31}$ These findings are consistent across studies, and mirror the pattern of differences found in toxicant content analyses of waterpipe and cigarette smoke in the analytical laboratory. For example, on a nicotinenormalised basis, waterpipe smoke contains much more CO, more PAHs and less TSNAs than cigarette smoke, and comparison of exposure biomarkers in the blood and urine of waterpipe and cigarette smokers reflects this pattern. Thus, we now know that waterpipe users inhale and absorb a significant toxicant load from WTS, including toxicants that are known to cause dependence, cancer, and heart and lung disease in cigarette smokers. It should be expected, then, that regular WTS use will result in deleterious health outcomes. ${ }^{55}$

An important facet of scientific work is communication of results. As in this review, investigators of WTS components have commonly reported toxicant yields from a waterpipe smoking session alongside those from a single cigarette. While comparison of yields is insufficient for assessing relative risk, there is a rationale underlying the presentation of WTS toxicant yields alongside cigarette yields as a risk communication strategy. For example, confronted by a finding that a single waterpipe use session produces $600 \mathrm{ng}$ of carcinogenic PAHs, the question immediately presented to the policymaker or layperson is whether this quantity represents a significant exposure burden. Given that carcinogenic PAHs are key agents in the aetiology of lung cancer, presenting this finding as 'several cigarettes worth of PAH' places the result in a context that is intelligible to the non-expert; the numbers become a cautionary red flag. While signalling WTS as hazardous is an appropriate use of toxicant yield data, we also caution that toxicant yield comparisons across tobacco products do not generally address whether one tobacco use method is more harmful than another. 


\section{CONCLUSION}

Every study to date has found that WTS contains ample quantities of toxicants known to cause various diseases in cigarette smokers, including cancer, and that at least some of those toxicants are effectively absorbed by waterpipe users, and are found in their breath, blood and urine. While the evidence base on WTS toxicants and effects remains sparse compared with that of cigarettes, the consistency of the available evidence within and across scientific approaches reviewed here and elsewhere ${ }^{55}$ indicate that waterpipe use presents a significant health hazard, and that policies that limit the spread and use of waterpipes, whether or not they contain tobacco, are necessary and justified. The consistency of the data also suggests that this conclusion will not change as more evidence becomes available.

\section{What this paper adds}

- A small but growing literature on maassel waterpipe smoke toxicants has developed over the past decade to address this global, rapidly growing tobacco use method.

- Reports of waterpipe toxicants and properties have not yet been compiled or compared comprehensively.

- Waterpipe smoke has been found to contain significant quantities of several toxicant classes, including nicotine and 27 known or suspected carcinogens.

- Waterpipe smoke is deleterious to human lung and arterial cells.

- Except for nicotine, smoke from tobacco-free waterpipe products has the same toxicant content and biological activity as that from tobacco-based products.

- Where data are available, exposure biomarker studies in waterpipe users corroborate patterns in toxicant yields reported in studies of waterpipe smoke.

- While toxicant quantities vary widely across studies, all available data to date indicate that waterpipe tobacco smoke, as well as smoke generated via popular tobacco-free waterpipe products, are hazardous substances.

Acknowledgements The authors gratefully acknowledge the editorial assistance of Ms Rima Baalbaki and Mr Mohammad Baasiri of the American University of Beirut.

Contributors AS, NAS, JK, JS, MES and AL compiled, extracted and reviewed the data for this study. AS drafted the Introduction, Background, Physical Properties, Comparison of Tobacco to Tobacco Free waterpipe smoke, Discussion and Conclusions sections. NAS, JS and JK drafted the Toxicants section and subsections. MES drafted the biological effects section. All authors shared in the conceptualisation of the study and editing the final manuscript. AS coordinated the overall effort.

Funding This work was supported by the National Institute on Drug Abuse of the National Institutes of Health and the Center for Tobacco Products of the US Food and Drug Administration under Award Numbers (P50DA036105, R01DA025659), and by the Office of the Dean, Faculty of Engineering \& Architecture, American University of Beirut.

\section{Competing interests None.}

Provenance and peer review Commissioned; externally peer reviewed.

Open Access This is an Open Access article distributed in accordance with the Creative Commons Attribution Non Commercial (CC BY-NC 4.0) license, which permits others to distribute, remix, adapt, build upon this work non-commercially, and license their derivative works on different terms, provided the original work is properly cited and the use is non-commercial. See: http://creativecommons.org/ licenses/by-nc/4.0/

\section{REFERENCES}

1 AkI EA, Gaddam S, Gunukula SK, et al. The effects of waterpipe tobacco smoking on health outcomes: a systematic review. Int I Epidemiol 2010;39:834-57.

2 Al Rashidi M, Shihadeh A, Saliba NA. Volatile aldehydes in the mainstream smoke of the narghile waterpipe. Food Chem Toxicol 2008;46:3546-9.

3 Apsley A, Galea KS, Sánchez-Jiménez A, et al. Assessment of polycyclic aromatic hydrocarbons, carbon monoxide, nicotine, metal contents and particle size distribution of mainstream Shisha smoke. JEHR 2011;11:93-104.

4 Amor MBEH, Ben Salah L, Khlifi S, et al. Identification of 11 polycyclic aromatic hydrocarbons and 4-(methylnitrosamino)-1-(3-pyridyl)-1-butanone in nargghile smoke. J Liq Chromatogr Relat Technol 2014;37:2206-17.

5 El-Aasar AM, El-Marzabani M. Studies on jurak smoke: I. The organic constituents of jurak smoke. J King Abdulaziz Univ (Sci) 1991;3:169-81.

6 El-Aasar AM, El-Marzabani M, Ba-Akel H. Studies on jurak smoke: II. The metallic constituents of jurak paste and jurak smoke. J King Abdulaziz Univ (Sci) 1991;3:183-8.

7 Hammal F, Chappell A, Wild TC, et al. 'Herbal' but potentially hazardous: an analysis of the constituents and smoke emissions of tobacco-free waterpipe products and the air quality in the cafés where they are served. Tob Control doi:10.1136/tobaccocontrol-2013-051169.

8 Markowicz P, Londahl J, Wierzbicka A, et al. A study on particles and some microbial markers in waterpipe tobacco smoke. Sci Total Environ 2014;499:107-13.

9 Monzer B, Sepetdjian E, Saliba N, et al. Charcoal emissions as a source of CO and carcinogenic PAH in mainstream narghile waterpipe smoke. Food Chem Toxicol 2008;46:2991-5

10 Saleh R, Shihadeh A. Elevated toxicant yields with narghile waterpipes smoked using a plastic hose. Food Chem Toxicol 2008;46:1461-6.

11 Schubert J, Bewersdorff J, Luch A, et al. Waterpipe smoke: a considerable source of human exposure against furanic compounds. Anal Chim Acta 2012;709:105-12.

12 Schubert J, Hahn J, Dettbarn G, et al. Mainstream smoke of the waterpipe: does this environmental matrix reveal as significant source of toxic compounds? Toxicol Lett 2011;205:279-84

13 Schubert J, Heinke V, Bewersdorff J, et al. Waterpipe smoking: the role of humectants in the release of toxic carbonyls. Arch Toxicol 2012;86:1309-16.

14 Schubert J, Kappenstein 0 , Luch A, et al. Analysis of primary aromatic amines in the mainstream waterpipe smoke using liquid chromatography-electrospray ionization tandem mass spectrometry. J Chromatogr A 2011;1218:5628-37.

15 Schubert J, Luch A, Schulz TG. Waterpipe smoking: analysis of the aroma profile of flavored waterpipe tobaccos. Talanta 2013;115:665-74.

16 Schubert J, Müller F, Schmidt R, et al. Waterpipe smoke: source of toxic and carcinogenic VOCs, phenols and heavy metals? Arch Toxicol Published Online First: 24 Sep 2014. doi:10.1007/s00204-014-1372-x.

17 Sepetdjian E, Abdul Halim R, Salman R, et al. Phenolic compounds in particles of mainstream waterpipe smoke. Nicotine Tob Res 2013;15:1107-12.

18 Sepetdjian E, Shihadeh A, Saliba NA. Measurement of 16 polycyclic aromatic hydrocarbons in narghile waterpipe tobacco smoke. Food Chem Toxicol 2008:46:1582-90.

19 Shihadeh A. Investigation of mainstream smoke aerosol of the argileh water pipe Food Chem Toxicol 2003;41:143-52.

20 Shihadeh A, Azar S. A closed-loop control "playback" smoking machine for generating mainstream smoke aerosols. J Aerosol Med 2006;19:137-47.

21 Shihadeh A, Saleh R. Polycyclic aromatic hydrocarbons, carbon monoxide, "tar", and nicotine in the mainstream smoke aerosol of the narghile water pipe. Food Chem Toxicol 2005;43:655-61.

22 Shihadeh A, Salman R, Jaroudi E, et al. Does switching to a tobacco-free waterpipe product reduce toxicant intake? A crossover study comparing $\mathrm{CO}, \mathrm{NO}, \mathrm{PAH}$, volatile aldehydes, "tar" and nicotine yields. Food Chem Toxicol 2012;50:1494-8.

23 Rammah M, Dandachi F, Salman R, et al. In vitro cytotoxicity and mutagenicity of mainstream waterpipe smoke and its functional consequences on alveolar type II derived cells. Toxicol Lett 2012;211:220-31.

24 Rammah M, Dandachi F, Salman R, et al. In vitro effects of waterpipe smoke condensate on endothelial cell function: a potential risk factor for vascular disease. Toxicol Lett 2013;219:133-42.

25 Shihadeh A, Eissenberg T, Rammah M, et al. Comparison of tobacco-containing and tobacco-free waterpipe products: effects on human alveolar cells. Nicotine Tob Res 2014;16:496-9.

26 Al Ali R, Rastam S, Ibrahim I, et al. A comparative study of systemic carcinogen exposure in waterpipe smokers, cigarette smokers and non-smokers. Tob Control 2013.

27 Bentur L, Hellou E, Goldbart A, et al. Laboratory and clinical acute effects of active and passive indoor group water-pipe (narghile) smoking. Chest 2014;145:803-9.

28 Eissenberg T, Shihadeh A. Waterpipe tobacco and cigarette smoking: direct comparison of toxicant exposure. Am J Prev Med 2009;37:518-23.

29 Helen GS, Benowitz NL, Dains KM, et al. Nicotine and carcinogen exposure after water pipe smoking in hookah bars. Cancer Epidemiol Biomarkers 2014:23:1055-66.

30 Jacob P III, Abu Raddaha AH, Dempsey D, et al. Nicotine, carbon monoxide, and carcinogen exposure after a single use of a water pipe. Cancer Epidemiol Biomarkers Prev 2011;20:2345-53. 
31 Jacob P III, Abu Raddaha AH, Dempsey D, et al. Comparison of nicotine and carcinogen exposure with water pipe and cigarette smoking. Cancer Epidemiol Biomarkers Prev 2013;22:765-72.

32 WHO. Advisory note: waterpipe tobacco smoking: health effects, research needs, and recommended actions by regulators. Geneva: WHO Study Group on Tobacco Product Regulation, 2005.

33 Maziak W. The global epidemic of waterpipe smoking. Addict Behav 2011;36:1-5.

34 Sepetdjian E, Saliba N, Shihadeh A. Carcinogenic PAH in waterpipe charcoal products. Food Chem Toxicol 2010;48:3242-5.

35 Katurji M, Daher N, Sheheitli $H$, et al. Direct measurement of toxicants inhaled by water pipe users in the natural environment using a real-time in situ sampling technique. Inhal Toxicol 2010;22:1101-9.

36 Shihadeh A, Azar S, Antonios C, et al. Towards a topographical model of narghile water-pipe cafe smoking: a pilot study in a high socioeconomic status neighborhood of Beirut, Lebanon. Pharmacol Biochem Behav 2004;79:75-82.

37 Maziak W, Rastam S, Shihadeh A, et al. Nicotine exposure in daily waterpipe smokers and its relation to puff topography. Addict Behav 2011;36:397-9.

38 Alzoubi KH, Khabour OF, Azab M, et al. CO exposure and puff topography are associated with Lebanese waterpipe dependence scale score. Nicotine Tob Res 2013;15:1782-6.

39 Blank MD, Cobb CO, Kilgalen B, et al. Acute effects of waterpipe tobacco smoking: a double-blind, placebo-control study. Drug Alcohol Depend 2011;116:102-9.

40 Shihadeh A, Eissenberg T. Significance of smoking machine toxicant yields to blood-level exposure in water pipe tobacco smokers. Cancer Epidemiol Biomarkers Prev 2011;20:2457-60.

41 Cobb CO, Sahmarani K, Eissenberg T, et al. Acute toxicant exposure and cardiac autonomic dysfunction from smoking a single narghile waterpipe with tobacco and with a "healthy" tobacco-free alternative. Toxicol Lett 2012;215:70-5.

42 Sutton SR, Russell MA, lyer R, et al. Relationship between cigarette yields, puffing patterns, and smoke intake: evidence for tar compensation? BMJ (Clin Res Ed) 1982;285:600-3.
43 Rodgman A, Perfetti TA. The chemical components of tobacco and tobacco smoke. 2nd edn. Boca Raton, Florida: CRC Press, 2013.

44 Hoffmann D, Hoffmann I. Letters to the Editor, Tobacco smoke components. Beitr Tabakforschung Int/ 1998;18:49-52.

45 Radwan G, Hecht SS, Carmella SG, et al. Tobacco-specific nitrosamine exposures in smokers and nonsmokers exposed to cigarette or waterpipe tobacco smoke. Nicotine Tob Res 2013;15:130-8.

46 Fowles J, Dybing E. Application of toxicological risk assessment principles to the chemical constituents of cigarette smoke. Tob Control 2003;12:424-30.

47 Liu C, Hu J, McAdam KG. A feasibility study on oxidation state of arsenic in cut tobacco, mainstream cigarette smoke and cigarette ash by $\mathrm{X}$-ray absorption spectroscopy. Spectrochim Acta B 2009;64:1294-301.

48 Intorp M, Purkis SW, Whittaker M, et al. Determination of "Hoffmann Analytes" in cigarette mainstream smoke. The Coresta 2006 Joint Experiment. Beitr Tabakforschung Int/ 2009;23:161-202.

49 Roemer $E$, Schramke $H$, Weiler $H$, et al. Mainstream smoke chemistry and in vitro and in vivo toxicity of the reference cigarettes $3 \mathrm{R} 4 \mathrm{~F}$ and $2 \mathrm{R} 4 \mathrm{~F}$. Beitr Tabakforschung Intl 2012;25:316-35.

50 Smith CJ, Dooly GL, Moldoveanu SC. New technique using solid-phase extraction for the analysis of aromatic amines in mainstream cigarette smoke. J Chromatogr $A$ 2003;991:99-107.

51 Hinds W, First MW, Huber GL, et al. A method for measuring respiratory deposition of cigarette smoke during smoking. Am Ind Hyg Assoc J 1983;44:113-18.

52 Robinson RJ, Yu CP. Deposition of cigarette smoke particles in the human respiratory tract. Aerosol Sci Tech 2001;34:202-15.

53 Monn C, Kindler P, Meile A, et al. Ultrafine particle emissions from waterpipes. Tob Control 2007;16:390-3.

54 Becquemin $\mathrm{MH}$, Bertholon JF, Attoui M, et al. [Particle size in water pipe smoke]. Rev Mal Respir 2008;25:839-46.

55 El Zaatari ZM, Chami HA, Zaatari GS. Health effects associated with waterpipe smoking. Tob Control 2015;24:i31-43. 